\title{
Evidence for a Role of Cyclic AMP and Endothelium in Rat Aortic Relaxa- tion Induced by R-PIA
}

\author{
Gonzalo Allende* and Salvador Acevedo
}

\author{
Department of Physiology and Pharmacology, Basic Sciences Center, Autonomous University of Aguascalientes, Av \\ Universidad 940, Aguascalientes, Ags, 20131 Mexico
}

\begin{abstract}
It is known that vasodilator effects of adenosine are mediated by $\mathrm{A}_{2}$ receptors in various animal species. Nevertheless, in several blood vessels there is evidence for vasodilator responses to some adenosine analogues, which are resistant to the antagonists of the different adenosine receptor subtypes, suggesting that they are not mediated by any of the known adenosine receptors. There are contradictory reports about the effects produced by adenosine and its analogues on aortic vasodilation. The results obtained in the present study dealing with rat aortic rings and the relaxant effects induced by the selective adenosine $\mathrm{A}_{1}$ receptor agonist $\mathrm{N}^{6}$-R-phenylisopropyladenosine (R-PIA) provide evidence that cyclic AMP and the presence of endothelium are possibly involved in rat aortic relaxation induced by this adenosine analogue.
\end{abstract}

Keywords: Aortic relaxation, adenosine, receptors, vasodilation, cyclic AMP, endothelium.

\section{INTRODUCTION}

It is widely known that adenosine has an important role in vasodilation in most of blood vessels [1, 2]. It has been established that relaxant responses elicited by adenosine and its analogues are mediated by $\mathrm{A}_{2 \mathrm{~A}}$ or $\mathrm{A}_{2 \mathrm{~B}}$ receptors $[3,4]$. The vasodilator effects of adenosine in coronary vessels are mediated by $\mathrm{A}_{2 \mathrm{~A}}$ receptors $[5,6]$, while adenosine-induced aortic relaxation in mice is produced through the activation of $A_{2 B}$ receptor subtype [5]. However, a number of experiments using aortic rings isolated from different animal species have shown that relaxant effects evoked by adenosine analogues are resistant to adenosine receptor antagonists [7-11], suggesting that such effects are not mediated by any of the adenosine receptors at present identified $[12,13]$.

Our research group, trying to find a possible attenuating effect of rat aortic relaxation mediated by $\mathrm{A}_{1}$ adenosine receptors (the attempt was unsuccessful), confirmed the latter assumption with data indicating that rat aortic vasodilation produced by the $A_{1}$ receptor agonist $\mathrm{N}^{6}-\mathrm{R}-$ phenylisopropyladenosine (R-PIA), or by the $\mathrm{A}_{2}$ receptor agonist 5'-N-ethylcarboxiamidoadenosine (NECA), can not be inhibited using $\mathrm{A}_{1}, \mathrm{~A}_{2 \mathrm{~A}}$ or $\mathrm{A}_{2 \mathrm{~B}}$ receptors selective antagonists. There are contradictory reports about the effects of adenosine and its analogues over aortic relaxation. Mustafa and his colleagues found that the vasodilator action of adenosine is mediated by $\mathrm{A}_{2 \mathrm{~B}}$ adenosine receptor subtype [4, 5], whilst Prentice's research group reported that adenosine dilatory effects do not involve adenosine $\mathrm{A}_{1}, \mathrm{~A}_{2}$ or $\mathrm{A}_{3}$ receptors $[8,9,11,13]$. These last authors also concluded that rat aortic relaxation induced by the agonist NECA, which binds

\footnotetext{
*Address correspondence to this author at the Department of Physiology and Pharmacology, Basic Sciences Center, Autonomous University of Aguascalientes, Av Universidad 940, Aguascalientes, Ags, 20131 Mexico; Tel: (52) 449 9108407; Fax: (52) 449 9108401;

E-mail: gdealle@correo.uaa.mx; gonzouaa@yahoo.com
}

with the same affinity to $A_{1}$ and $A_{2}$ adenosine receptors, is produced through the activation of endothelial receptors to release nitric oxide (NO), which stimulates guanylate cyclase, as well as through the activation of smooth muscle receptors coupled to stimulation of adenylate cyclase, whereas neither of these mechanisms causes the vasodilator effects of R-PIA [14].

In the present work, experiments using several pharmacologic tools related to cyclic AMP signals transduction mechanism were conducted, and the results suggest that rat aortic relaxation evoked by R-PIA clearly depends, at least partially, on the increase of cyclic AMP levels, and this effect is also dependent on the presence of endothelium. Our results contrast with those described by Hourani et al. [14], who concluded that the vasodilation induced by R-PIA does not involve the stimulation of adenylate cyclase; they also differ from the data reported by Prentice et al. [13], who found that mouse aorta relaxation is independent of the presence of endothelium and nitric oxide production.

\section{MATERIALS AND METHODOLOGY}

Eleven to thirteen weeks old male Wistar rats weighing 200-250 g were sacrificed by deep anesthesia with sodium pentobarbital $(100 \mathrm{mg} / \mathrm{kg}$ ip) and the thoracic aorta was gently removed and then transversely cut into rings $2-3 \mathrm{~mm}$ long. The rings were mounted between two steel wire hooks and suspended in $8 \mathrm{ml}$ organ baths containing KrebsHenseleit solution (in $\mathrm{mM}: \mathrm{NaCl}, 118 ; \mathrm{KCl}, 4.7 ; \mathrm{MgSO}_{4}, 1.2$; $\mathrm{KH}_{2} \mathrm{PO}_{4}, 1.2 ; \mathrm{NaHCO}_{3}, 25 ; \mathrm{CaCl}_{2}: 2 \mathrm{H}_{2} \mathrm{O}, 2.5 ; \mathrm{D}$-glucose, 11), continually gassed with $95 \% \mathrm{O}_{2} / \mathrm{CO}_{2}$. Aortic rings were allowed to stabilize for $60 \mathrm{~min}$ at a resting tension of $0.75-1$ g. Tissue viability was tested using $0.1 \mu \mathrm{M}$ phenylephrine, a concentration that elicits approximately $80 \%$ of maximum contraction [15]. All rings were tested for the presence of functional endothelium using $1 \mu \mathrm{M}$ acetylcholine. Tissues in which acetylcholine induced less than a $25 \%$ decrease in contraction were rejected. In experiments where the effects 
of the absence of endothelium were investigated, the removal of endothelium was achieved by carefully rolling the aortic ring on a fine tungsten wire; the absence of endothelium was then confirmed by the loss of relaxant response to $1 \mu \mathrm{M}$ acetylcholine.

Concentration-response curves for aortic relaxation by RPIA or NECA were obtained by cumulative addition of agonists to organ baths containing the aortic rings pre-contracted with phenylephrine $(0.1 \mu \mathrm{M})$ or $\mathrm{KCl}(30 \mathrm{mM})$. The concentration in the organ bath was increased in 1-log concentration steps, and agonists were added to yield the next higher concentration only when the response to the earlier dose reached a steady state. Only one concentration-response curve was constructed in each preparation. Relaxant responses were expressed as the percent decrease in the contraction induced by phenylephrine or $\mathrm{KCl}$ in response to each concentration of the agonist. In the experiments using antagonists, two rings were taken from the same animal, one was used as a control and one as an antagonist-treated preparation. The adenosine receptor antagonists used were: 1,3-dipropyl-8cyclopentylxanthine(DPCPX, $\mathrm{A}_{1}$ receptor antagonist) (100 $\mu \mathrm{M})$; SCH-58261 (100 $\mu \mathrm{M})$ and 8-3-chlorostyryl-caffeine (CSC) $(100 \mu \mathrm{M})$, both $\mathrm{A}_{2 \mathrm{~A}}$ receptor antagonists; and MRS$1754(100 \mu \mathrm{M})\left(\mathrm{A}_{2 \mathrm{~B}}\right.$ receptor antagonist). The antagonists were added $60 \mathrm{~min}$ before contractions of the rings with phenylephrine.

For cyclic AMP signaling experiments, rings were precontracted with $30 \mathrm{mM} \mathrm{KCl}$ instead of phenyleprine to avoid any possible cross interaction of this adrenergic agonist with the different pharmacological tools used to study aortic relaxation induced by R-PIA. Before pre-contraction with 30 $\mathrm{mM} \mathrm{KCl}$, the aortic rings were incubated for $45 \mathrm{~min}$ with the following inhibitors: $100 \mu \mathrm{M}$ SQ-22536, $100 \mu \mathrm{M}$ Ro 201724 and $10 \mu \mathrm{M}$ KT-5720. Two punctual additions of dibutyryl cyclic-AMP $(50 \mu \mathrm{M})$ were done simultaneously with the R-PIA concentration-response experiment (at $10^{-7}$ and $10^{-4} \mathrm{M}$ R-PIA concentrations, respectively). For pertussis toxin (PTX) experiments, animals were injected with PTX (25 $\mu \mathrm{g} / 100 \mathrm{~g}$ ip) 3 days before the sacrifice to obtain the aortic segments. In all the experiments, animals were handled according to the Institutional Normative Welfare Standards (University of Aguascalientes). Signaling experiments were performed in parallel using two aortic rings from the same vessel; one served as a control (not treated) and one served as the treatment.

Changes in isometric tension were measured with a fixed-range force transducer (model R3804, Radnoti) connected to a differential amplifier (model 7173 Transducer Coupler + model 7070 Channel Amplifier, NarcoBiosystems). Data were recorded on a Hewlett Packard computer using a MP 100 WSW digital acquisition system (BIOPAC Systems) and were analyzed using Acqknowledge 3.7.4 software (BIOPAC Systems). Data are expressed as means \pm S.E.M. of values obtained from at least three different animals. Results for adenosine analogues (R-PIA and NECA) and the effects of antagonists or drugs treatment are presented as the percentage decreases in the contraction induced by phenylephrine $(0.1 \mu \mathrm{M})$ or $\mathrm{KCl}(30 \mathrm{mM})$. Statistical differences between means were assessed by Student's ttest and $P$ values of less than 0.05 were considered significant.
All chemicals were purchased from Sigma-Aldrich (St. Louis, MO) and used at stock concentrations of $10 \mathrm{mM}$. Phenylephrine, acetylcholine and dibutyryl cyclic-AMP were dissolved in distilled water; R-PIA in 50\% dimethylsulphoxide (DMSO); NECA, DPCPX, CSC, MRS-1754 and SQ22536 in $100 \%$ DMSO; SCH-58261 in 80\% DMSO; Ro 201724 and KT-5720 were initially dissolved in a minimal volume $(40 \mu \mathrm{l})$ of ethanol and methanol, and were then diluted in distilled water to obtain stock concentrations of $10 \mathrm{mM}$ and $1 \mathrm{mM}$, respectively. Further serial dilutions were made in distilled water. The final concentrations of DMSO, ethanol and methanol in the $8 \mathrm{ml}$ organ bath chamber had no effect by themselves on the aortic rings responses.

\section{RESULTS}

Cumulative relaxant curves for R-PIA and NECA were constructed in rings contracted with $0.1 \mu \mathrm{M}$ phenylephrine. As shown in Figs. (1) and (2), relaxant responses to R-PIA and NECA were observed at concentrations above $10^{-7} \mathrm{M}$. Fig. (1) shows that vasodilator effects induced by the $A_{1}$ receptor agonist R-PIA were not significantly affected by the treatment with DPCPX ( $\mathrm{A}_{1}$ antagonist), $\mathrm{SCH}-58261 \quad\left(\mathrm{~A}_{2 \mathrm{~A}}\right.$ antagonist) or MRS-1754 ( $\mathrm{A}_{2 \mathrm{~B}}$ antagonist). Similarly, relaxations elicited by the agonist NECA (same affinity for $\mathrm{A}_{1}$ and $\mathrm{A}_{2}$ receptor subtypes) were unaffected by DPCPX, MRS1754 or $\operatorname{CSC}\left(\mathrm{A}_{2 \mathrm{~A}}\right.$ antagonist) (Fig. 2).

In aortic rings contracted with $30 \mathrm{mM} \mathrm{KCl}$, the adenylate cyclase inhibitor SQ-22536 $(100 \mu \mathrm{M})$ produced a significant rightward shift in the concentration-response curve to R-PIA, diminishing the relaxation evoked by this agonist (Fig. 3). $\mathrm{EC}_{50}$ values for R-PIA increased from $1.99 \times 10^{-5} \mathrm{M}$ to 1.25 $\mathrm{X} 10^{-4} \mathrm{M}$ in presence of the inhibitor.Maximum relaxation obtained with R-PIA $\left(10^{-4} \mathrm{M}\right)$ was $84.0 \pm 8.8 \%$, while SQ22536 caused a decrease to $55.7 \pm 4.9 \%$ (Fig. 3). However, after removal of endothelium, SQ-22536 did not inhibit the responses to R-PIA (Fig. 4). It is important to point out that, in the absence of endothelium, R-PIA only caused a signifi-

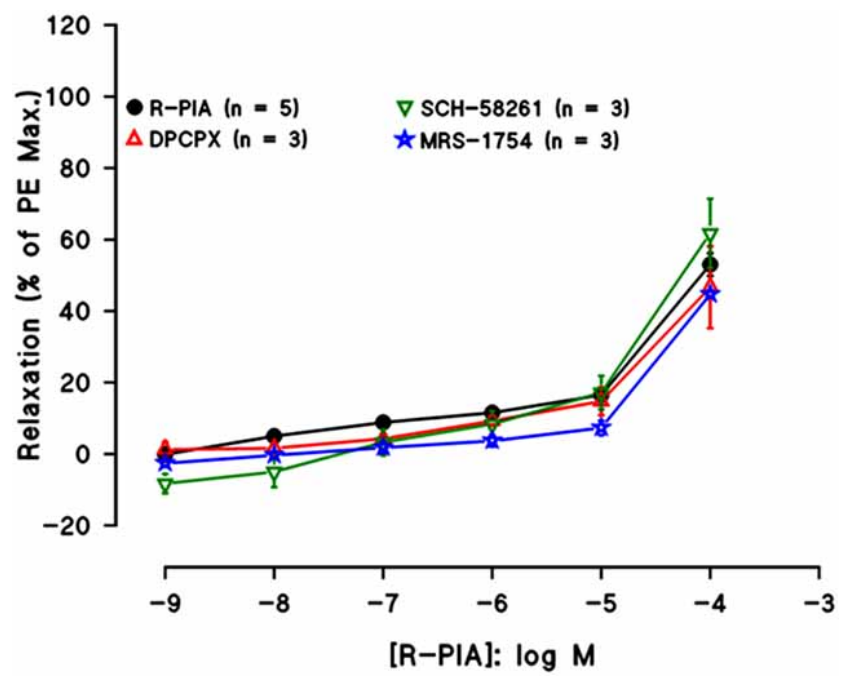

Fig. (1). Concentration-response curves to R-PIA in the absence $(\bullet)$ or presence of $100 \mu \mathrm{M} \operatorname{DPCPX}(\triangle), 100 \mu \mathrm{M} \mathrm{SCH}-58261(\nabla)$ or $100 \mu \mathrm{M}$ MRS-1754 ( $\star$ ). Each point represents the mean \pm SE $(\%$ relaxation of phenylephrine-induced contraction). For abbreviations, see text. 


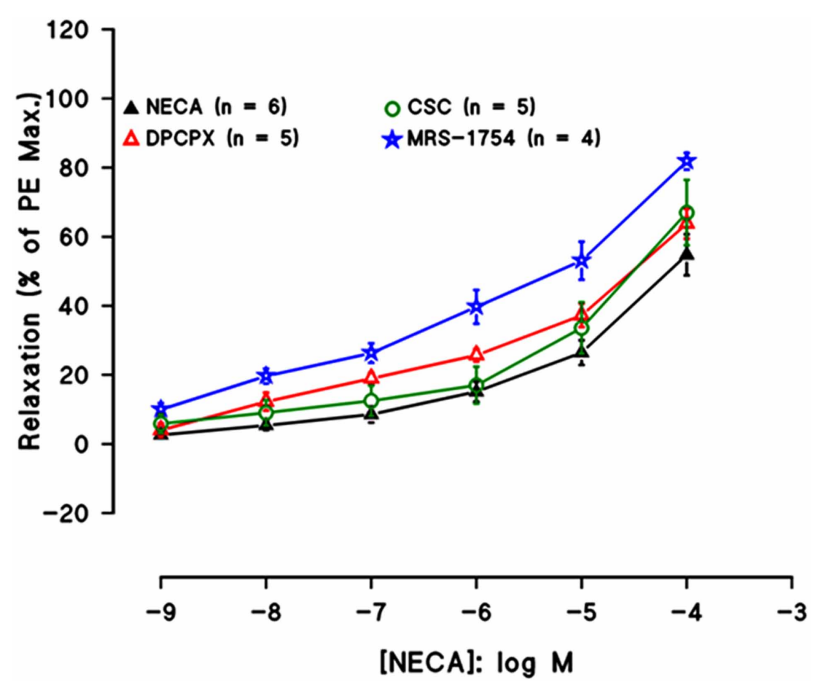

Fig. (2). Concentration-response curves to NECA in the absence $(\boldsymbol{\Delta})$ or presence of $100 \mu \mathrm{M} \operatorname{DPCPX}(\triangle), 100 \mu \mathrm{M} \mathrm{CSC}(\mathrm{O})$ or 100 $\mu \mathrm{M}$ MRS-1754 ( $\star$ ). Each point represents the mean \pm SE (\% relaxation of phenylephrine-induced contraction). For abbreviations, see text.

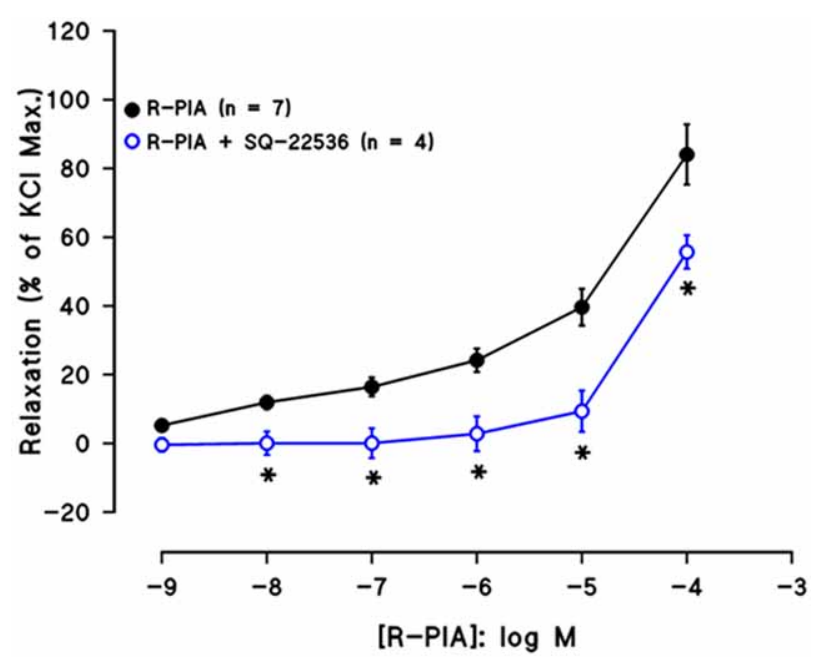

Fig. (3). Concentration-response curves to R-PIA in the absence (•) or presence of $100 \mu \mathrm{M}$ SQ-22536 (O), in endothelium-intact rat aortic rings. Each point represents the mean $\pm \mathrm{SE}$ (\% relaxation of $\mathrm{KCl}$-induced contraction). ${ }^{*} \mathrm{P}<0.05$ compared with R-PIA. For abbreviations, see text.

cant relaxant effect with the highest concentration used $\left(10^{-4}\right.$ M) (Fig. 4).

In contrast, the treatment of the aortic rings with the type IV phosphodiesterase inhibitor Ro 20-1724 $(100 \mu \mathrm{M})$ enhanced the vasodilation elicited by R-PIA, producing a very significant leftward shift in the concentration-response curve $\left(\mathrm{EC}_{50}=9.59 \times 10^{-6} \mathrm{M}\right.$ in the presence of the inhibitor and $\mathrm{EC}_{50}=4.23 \times 10^{-5} \mathrm{M}$ in its absence) (Fig. 5). Maximum relaxation induced by $10^{-4} \mathrm{M}$ R-PIA increased from $57.5 \pm$ $7.0 \%$ to $89.9 \pm 4.7 \%$ in the presence of Ro 20-1724 (Fig. 5). Likewise, additions of the analogous of cyclic AMP: dibutyryl cyclic-AMP $(50 \mu \mathrm{M})$ to the organ chamber also resulted in a significant leftward shift in the concentrationresponse curve to R-PIA, increasing its relaxing effects on

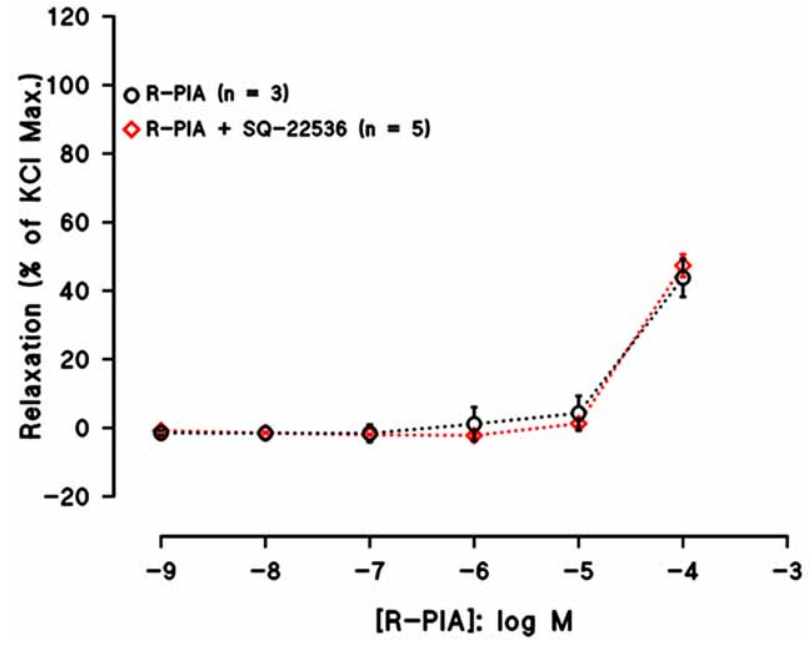

Fig. (4). Concentration-response curves to R-PIA in the absence (O) or presence of $100 \mu \mathrm{M}$ SQ-22536 $(\diamond)$, in endotheliumdenuded rat aortic rings. Each point represents the mean $\pm \mathrm{SE}(\%$ relaxation of KCl-induced contraction). For abbreviations, see text.

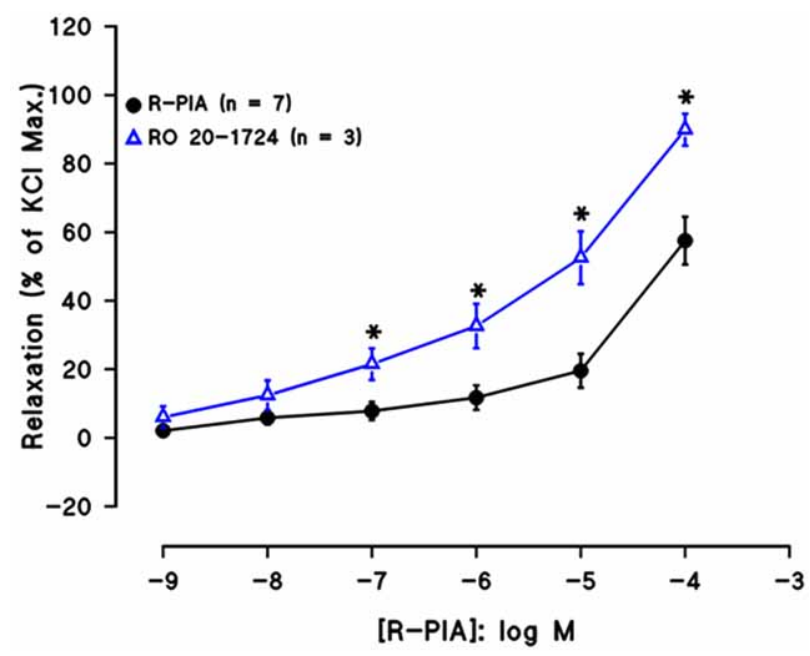

Fig. (5). Concentration-response curves to R-PIA in the absence (•) or presence of $100 \mu \mathrm{M}$ Ro $20-1724(\triangle)$. Each point represents the mean $\pm \mathrm{SE}$ (\% relaxation of $\mathrm{KCl}$-induced contraction). ${ }^{*} \mathrm{P}<0.05$ compared with R-PIA. For abbreviations, see text.

both endothelium-intact and endothelium-denuded rat aortic rings (Figs. 6 and 7). Dibutyryl cyclic-AMP also reduced $\mathrm{EC}_{50}$ values for R-PIA and produced significant rises of the maximum relaxations evoked by R-PIA in both preparations (Figs. 6 and 7).

Supporting the latter results, cumulative concentrationresponse curves constructed for R-PIA and dibutyryl cyclicAMP show that they elicited a very similar concentrationdependent relaxation (Fig. 8), whereas the combined action of both reagents had an evident synergistic relaxing effect: $\mathrm{EC}_{50}$ values diminished to $2.66 \times 10^{-5} \mathrm{M}$ and the maximum relaxation increased to $109.4 \pm 3.8 \%$, in comparison with relaxations induced separately by R-PIA and dibutyryl cyclic-AMP (Fig. 8).

Fig. (9) shows the enhancing effects of pertussis toxin (PTX) on vasodilation produced by R-PIA. Aortic rings isolated from animals previously injected with PTX, showed a 


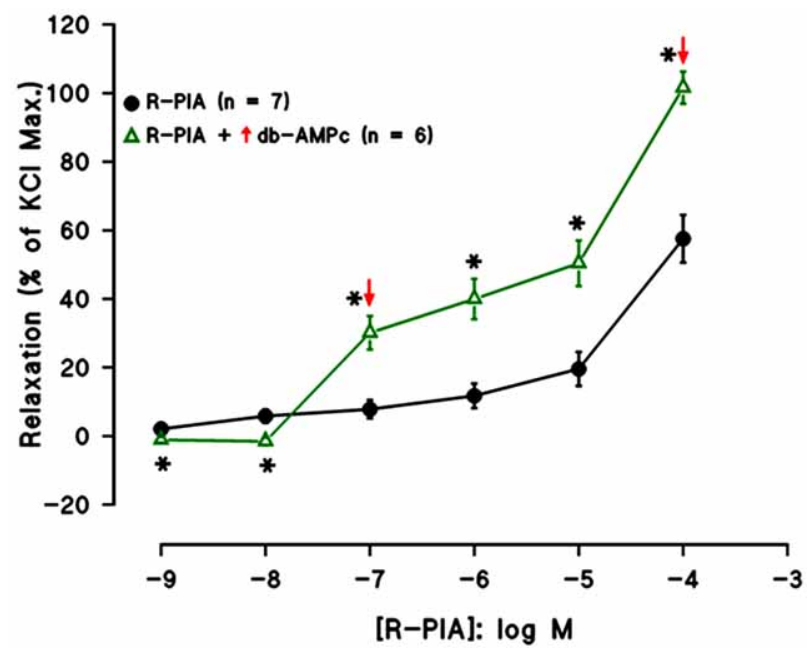

Fig. (6). Concentration-response curves to R-PIA alone $(\bullet)$ or with two punctual additions $(\downarrow)$ of $50 \mu \mathrm{M}$ dibutyryl cyclic-AMP $(\triangle)$, in endothelium-intact rat aortic rings. Each point represents the mean $\pm \mathrm{SE}$ (\% relaxation of $\mathrm{KCl}$-induced contraction). ${ }^{*} \mathrm{P}<0.05$ compared with R-PIA. For abbreviations, see text.

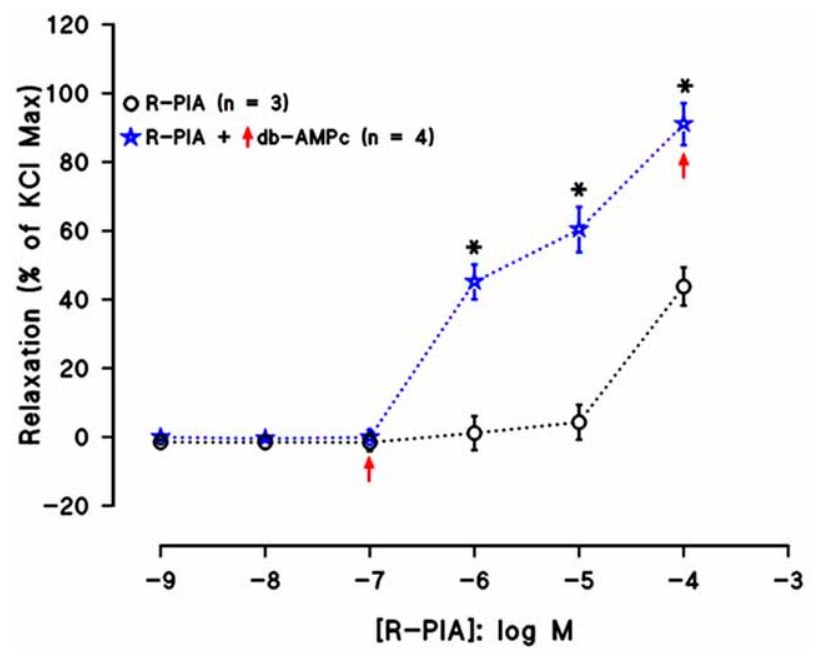

Fig. (7). Concentration-response curves to R-PIA alone $(\bullet)$ or with two punctual additions $(\downarrow)$ of $50 \mu \mathrm{M}$ dibutyryl cyclic-AMP $(\Delta)$, in endothelium-denuded rat aortic rings. Each point represents the mean $\pm \mathrm{SE}$ (\% relaxation of $\mathrm{KCl}$-induced contraction). ${ }^{*} \mathrm{P}<0.05$ compared with R-PIA. For abbreviations, see text.

significant decrease of $\mathrm{EC}_{50}$ value (from $2.73 \times 10^{-5} \mathrm{M}$ to $\left.7.93 \times 10^{-6} \mathrm{M}\right)$ and a significant increase of the maximum relaxation evoked by R-PIA (from $71.8 \pm 8.7 \%$ to $103.0 \pm$ $5.2 \%$ ), as compared with the control rings (Fig. 9). Interestingly, rings pre-incubation with the cAMP-dependent protein kinase (PKA) selective inhibitor KT-5720 $(10 \mu \mathrm{M})$ had no significant effects on the relaxation elicited by R-PIA (Fig. 10).

\section{DISCUSSION}

Preliminary experiments originally aimed to find a possible attenuating effect of rat aortic relaxation mediated by $A_{1}$ adenosine receptors just confirmed the concepts stated in several reports, that indicate that aortic vasodilation evoked by adenosine analogues in different animal species are resis- tant to adenosine receptor antagonists [7-11]. Our data showed that rat aortic relaxations induced by the selective adenosine $A_{1}$ receptor agonist: R-PIA, or by the $A_{2}$ receptor agonist: NECA, were resistant to blocking by $A_{1}, A_{2 A}$ or $A_{2 B}$ receptors selective antagonists (Figs. 1 and 2). These results are in complete agreement with those reported by Prentice et al. $[12,13]$, and, as a whole, they suggest that vasodilator effects produced by adenosine analogues in aortic rings isolated of several species, are not mediated by any of the adenosine receptors at present identified. It is reasonable to assume that such effects might be mediated by an unknown receptor activated by R-PIA and other adenosine analogues.

Therefore, experiments were conducted to determine whether the cyclic AMP signals transduction mechanism is involved in the aortic relaxation elicited by R-PIA, starting

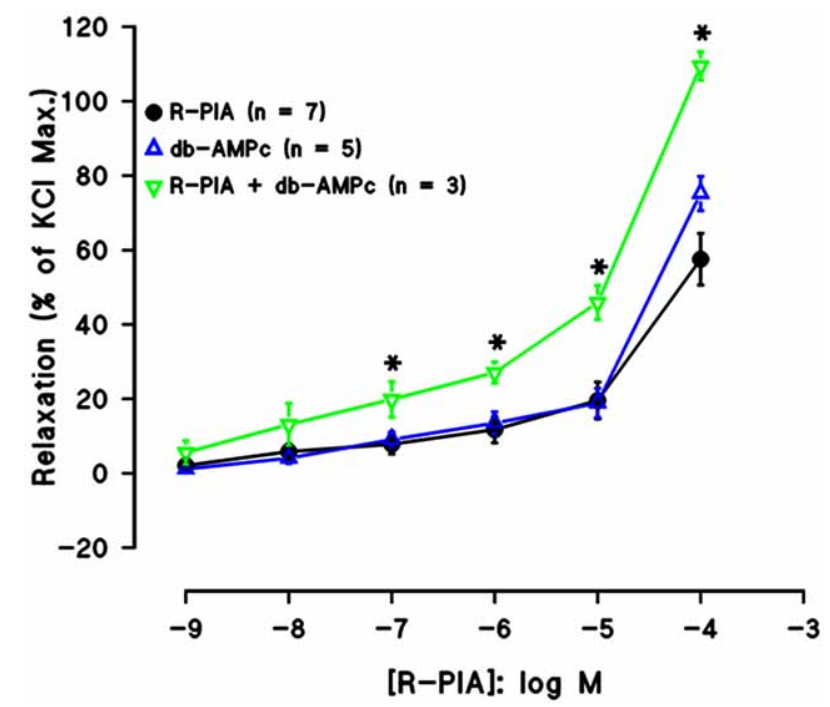

Fig. (8). Concentration-response curves to: R-PIA (•), dibutyryl cyclic-AMP $(\triangle)$, and R-PIA + dibutyryl cyclic-AMP $(\nabla)$ in endothelium-intact aorta. Each point represents the mean $\pm \mathrm{SE}(\% \mathrm{re}-$ laxation of $\mathrm{KCl}$-induced contraction). $* \mathrm{P}<0.05$ compared with $\mathrm{R}$ PIA. For abbreviations, see text.

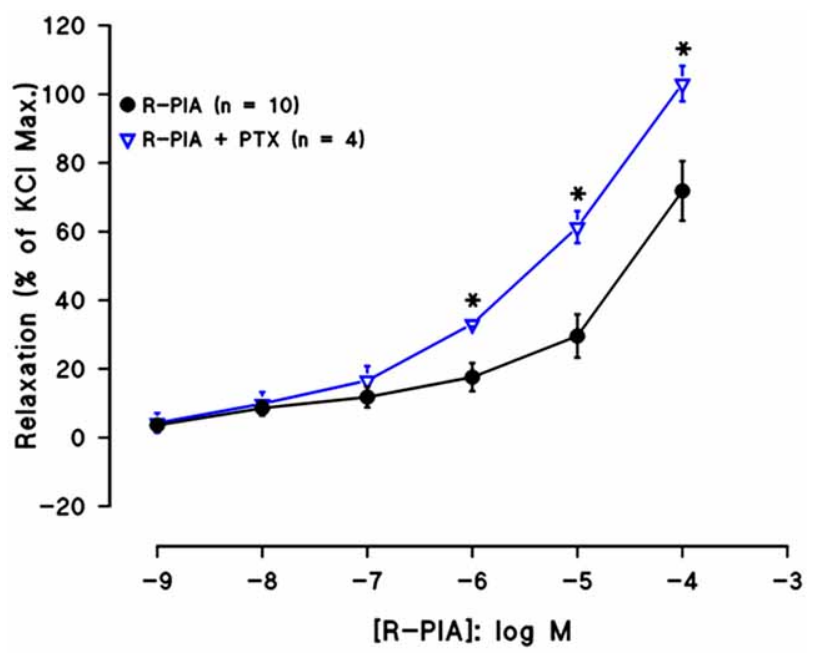

Fig. (9). Concentration-response curves to R-PIA alone (•), and to R-PIA in aortic rings isolated from rats treated with pertussis toxin $(\nabla)$. Each point represents the mean $\pm \mathrm{SE}(\%$ relaxation of $\mathrm{KCl}-$ induced contraction). ${ }^{*} \mathrm{P}<0.05$ compared with R-PIA. For abbreviations, see text. 


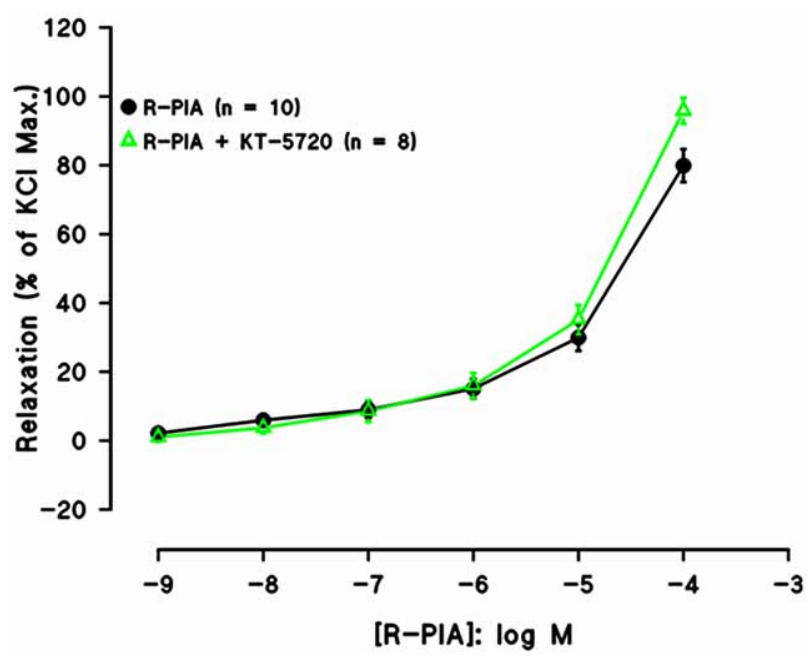

Fig. (10). Concentration-response curves to R-PIA in the absence $(\bullet)$ or presence of $10 \mu \mathrm{M} \mathrm{KT}-5720(\triangle)$. Each point represents the mean $\pm \mathrm{SE}$ (\% relaxation of $\mathrm{KCl}$-induced contraction). For abbreviations, see text.

from the assumption that adenosine and its analogues could cause vasodilation through stimulation of adenylate cyclase and the consequent increase of cyclic AMP levels.

In endothelium-intact aortic rings, the adenylate cyclase inhibitor SQ-22536 produced a significant inhibition of the aortic relaxants effects evoked by R-PIA (Fig. 3). These results are not consistent with those reported by Hourani et al. [14], since they indicated a lack of effect of SQ-22536, suggesting that the stimulation of adenylate cyclase is not essential for the relaxation induced by R-PIA [14]. As shown in Fig. (3), our data clearly suggest that adenylate cyclase has an evident role in rat aortic relaxation elicited by R-PIA. The experiments using SQ-22536 in endothelium-denuded aortic rings showed that endothelium presence is necessary to allow the vasodilation produced by R-PIA, since its relaxing action at concentrations from $10^{-8} \mathrm{M}$ to $10^{-5} \mathrm{M}$ virtually disappeared both in control and in inhibitor-treated rings (Fig. 4). As compared with endothelium-intact rings (Fig. 3), RPIA only induced a diminished relaxation at the higher concentration $\left(10^{-4} \mathrm{M}\right)$ in endothelium-denuded rings (Fig. 4).

The type IV phosphodiesterase is the enzyme responsible for degrading the cyclic AMP. The use of its inhibitor Ro 201724 increased the vasodilator effects evoked by R-PIA (Fig. 5), suggesting the involvement of cyclic AMP in these responses. Again, our results are slightly at variance with those reported by Hourani et al. [14], who only found a minor enhancement of the relaxation elicited by R-PIA in their experiments employing Ro 20-1724, although they also conclude that cyclic AMP is involved in the vasodilation produced by the agonist NECA [14]. In this respect, it could be assumed that R-PIA and NECA probably bind and activate the same hypothetical unknown receptor, since R-PIA is generally considered a selective $\mathrm{A}_{1}$ adenosine receptor agonist, whilst the agonist NECA binds with similar affinity to $A_{1}$ and $A_{2}$ adenosine receptors, and relaxant effects induced by both agonists can not be inhibited using $A_{1}, A_{2 A}$ or $A_{2 B}$ receptors selective antagonists (Figs. 1 and 2).

The results obtained with the analogous of cyclic AMP: dibutyryl cyclic-AMP, also supported the involvement of cyclic AMP in the relaxation evoked by R-PIA, since the use of the analogous enhanced its vasodilator effects on both endothelium-intact and endothelium-denuded rat aorta (Figs. 6 and 7). Moreover, the concentration-response experiments with R-PIA and dibutyryl cyclic-AMP showed that they elicited a very similar vasodilation, while the simultaneous use of both agents had larger relaxation effects, as compared with the responses induced separately by R-PIA and dibutyryl cyclic-AMP (Fig. 8).

Finally, we examined the effects of pertussis toxin (PTX) in order to obtain additional data proving the role of cyclic AMP in the aortic relaxation elicited by R-PIA. PTX catalyzes ADP-ribosylation of $\mathrm{G}_{\mathrm{i}}$ proteins, preventing GDP displacement by GTP and thus blocking inhibition of adenylate cyclase by $\mathrm{G}_{i}$, causing high concentrations of cyclic AMP. As shown in Fig. 9, the pre-treatment in vivo with PTX produced a significant increment of relaxation, starting from a concentration of $10^{-6} \mathrm{M}$ R-PIA, which substantiates the involvement of cyclic AMP levels in the vasodilator effects induced by R-PIA. This result is consistent with previous findings reported by many authors, which have widely shown that pertussis toxin relieves adenylate cyclase from the Gi inhibitory action, thus magnifying the action of agents that act through receptors coupled to Gs to stimulate the adenylate cyclase [16-18].

Altogether, the data obtained in our experiments with SQ-22536, Ro 20-1724, dibutyryl cyclic-AMP and pertussis toxin, clearly indicate the involvement of cyclic AMP in the aortic relaxation evoked by R-PIA, apparently through a mechanism which is endothelium-dependent, at least at the lower concentrations used in the assays. With the upper concentration of R-PIA, the vasodilation appears not to be endothelium-dependent, since the results using denuded aortic rings showed that $10^{-4} \mathrm{M}$ R-PIA produced significant relaxant effects (Figs. 4 and 7).

However, the pre-treatment of the aortic rings with the PKA selective inhibitor KT-5720 did not affect the relaxation elicited by R-PIA (Fig. 10). Although the rest of our results strongly suggest that aortic relaxation induced by $\mathrm{R}$ PIA depends on cyclic AMP levels, the data obtained using KT-5720 imply that PKA might not be involved in the vasodilation. In this respect, Hourani et al. indicated that vasodilator effects induced by NECA are endothelium-dependent and that this agonist acts at least partially through the endothelial release of nitric oxide (NO) [14]. These authors propose a model in which NECA acts through $\mathrm{A}_{2 \mathrm{~A}}$ receptors to cause both direct stimulation of adenylate cyclase in smooth muscle and stimulation of NO release from endothelial cells which causes an increase in cyclic GMP in the smooth muscle [14]. They also quoted the information obtained by other authors, in order to explain their results about rat aortic relaxation produced by NECA, and they remark that endothelium-dependent effects of NECA and the release of NO were possibly associated with the stimulation of an endothelial adenylate cyclase and the increase in cyclic AMP levels [14]. The latter assumption could also be a likely explanation for the aortic vasodilation evoked by R-PIA observed in our experiments.

According to the model proposed by Hourani et al.[14], our results could be explained assuming that aortic relaxation 
induced by R-PIA is due to the activation of a receptor located in endothelial cells, which in its turn stimulates adenylate cyclase (see our data with SQ-22536), increasing cyclic AMP levels to produce the aortic relaxation observed,but not through the activation of a cyclic AMP-dependent protein kinase (see our data with KT-5720); as the model of Hourani et al. [14] suggests for NECA induced relaxation, R-PIA could act through the stimulation of endothelial receptors to release NO, which stimulates guanylate cyclase to increase cyclic GMP in the smooth muscle. Nevertheless, the results shown in Fig. (7) do not support this assumption, since they indicate that cyclic AMP alone is capable to cause aortic relaxation in absence of endothelium. Therefore, further experiments assaying several pharmacological tools related to NO signaling pathway are necessary to determine its implication in rat aortic vasodilation evoked by R-PIA.

In summary, two major conclusions can be drawn from the present study: first, the rat aortic relaxation induced by R-PIA depends, at least partially, on cyclic AMP levels; and second, the receptor activated by R-PIA seems to be mainly located in endothelial cells. The activation of this endothelial receptor by R-PIA would stimulate adenylate cyclase with a consequent increase of cyclic AMP levels.

\section{ACKNOWLEDGEMENTS}

This study was supported by PIFF08-3N project from the Universidad Autónoma de Aguascalientes and UAA-CA-24 project from PROMEP. The authors thank Mrs. Nora Allende for her helpful editorial assistance.

\section{REFERENCES}

[1] Frobert, O.; Haink, G.; Simonsen, U.; Gravholt, C.H.; Levin, M.; Deussen, A. Adenosine concentration in the porcine coronary artery wall and $\mathrm{A}_{2 \mathrm{~A}}$ receptor involvement in hypoxia-induced vasodilation. J. Physiol., 2006, 570, 375-384.

[2] Sato, A.; Terata, K.; Miura, H.; Toyama, K.; Loberiza, F.R. Jr.; Hatoum, O.A.; Saito, T; Sakuma, I.; Gutterman, D.D. Mechanism of vasodilation to adenosine in coronary arterioles from patients with heart disease. Am. J. Physiol. Heart Circ. Physiol., 2005, 288, H1633-H1640.

[3] Ralevic, V.; Burnstock, G. Receptors for purines and pyrimidines. Pharmacol. Rev., 1998, 50, 413-492.
[4] Ansari, H.R.; Nadeem, A.; Talukder M.A.H.; Sakhalkar, S.; Mustafa, S.J. Evidence for the involvement of nitric oxide in $\mathrm{A}_{2 \mathrm{~B}}$ receptor-mediated vasorelaxation of mouse aorta. Am. J. Physiol. Heart Circ. Physiol., 2007, 292, H719-H725.

[5] Talukder, M.A.H.; Morrison, R.R.; Mustafa, S.J. Comparison of the vascular effects of adenosine in isolated mouse heart and aorta. Am. J. Physiol. Heart Circ. Physiol., 2002, 282, H49-H57.

[6] Morrison, R.R.; Talukder, M.A.H.; Ledent, C.; Mustafa, S.J. Cardiac effects of adenosine in $\mathrm{A}_{2 \mathrm{~A}}$ receptor knockout hearts: uncovering $\mathrm{A}_{2 \mathrm{~B}}$ receptors. Am. J. Physiol. Heart Circ. Physiol., 2002, 282, H437-H444.

[7] Collis, M.G.; Brown, C.M. Adenosine relaxes the aorta by interacting with an $\mathrm{A}_{2}$ receptor and an intracellular site. Eur. J. Pharmacol., 1983, 96, 61-69.

[8] Lewis, C.D.; Hourani, S.M.O.; Long, C.J.; Collis, M.G. Characterization of adenosine receptors in the rat isolated aorta. Gen. Pharmacol., 1994, 25, 1381-1387.

[9] Prentice, D.J.; Hourani, S.M.O. Characterization of adenosine receptors mediating relaxation in hamster isolated aorta. Naunyn Schmiedeberg's Arch. Pharmacol., 2000, 362, 427-434.

[10] Knight, G.E.; Burnstock, G. The effects of purine compounds on the isolated aorta of the frog Rana temporaria. Br. J. Pharmacol., 1996, 117, 873-878.

[11] Prentice, D.J.; Kelly, M.D.W.; Ledent, C.; Hourani, S.M.O. Relaxation of the mouse isolated aorta and carotid artery in response to adenosine analogues in genetically-modified mice lacking adenosine $\mathrm{A}_{2 \mathrm{~A}}$ receptor. Naunyn Schmiedeberg's Arch. Pharmacol., 2002, 366, 127-133.

[12] Prentice, D.J. Vascular effects of adenosine and its analogues Drug Dev. Res., 2001, 52, 346-349.

[13] Prentice, D.; Boon, K.; Hourani, S. Relaxation of mouse isolated aorta to adenosine and its analogues does not involve adenosine $\mathrm{A}_{1}$, $\mathrm{A}_{2}$ or $\mathrm{A}_{3}$ receptors. Eur. J. Pharmacol., 2001, 415, 251-255.

[14] Hourani, S.M.O.; Boon, K.; Fooks, H.M.; Prentice, D.J. Role of cyclic nucleotides in vasodilations of the rat thoracic aorta induced by adenosine analogues. Br. J. Pharmacol., 2001, 133, 833-840.

[15] Prentice, D.J.; Hourani, S.M.O. Activation of multiple sites by adenosine analogues in the rat isolated aorta. Br. J. Pharmacol., 1996, $118,1509-1517$.

[16] Katada, T.; Ui, M. Direct modification of the membrane adenylate cyclase system by islet- activating protein due to ADP-ribosylation of a membrane protein. Proc. Natl. Acad. Sci. U.S.A., 1982, 79, 3129-3133.

[17] Katada, T.; Amano T.; Ui, M. Modulation by islet-activating protein of adenylate ciclase activity in C6 glioma cells. J. Biol. Chem., 1982, 257, 3739-3746

[18] Martínez-Olmedo, M.A.; García-Sáinz, J.A. Effect of pertussis toxin on the hormonal regulation of cyclic AMP levels in hamster fat cells. Biochim. Biophys. Acta, 1983, 760, 215-220. 